\title{
Estimating changes in daily physical activity levels over time: implication for health interventions from a novel approach
}

Citation for published version (APA):

Vogels, N., Egger, G., Plasqui, G., \& Westerterp, K. R. (2004). Estimating changes in daily physical activity levels over time: implication for health interventions from a novel approach. International Journal of Sports Medicine, 25(8), 607-610. https://doi.org/10.1055/s-2004-820950

Document status and date:

Published: 01/01/2004

DOI:

10.1055/s-2004-820950

Document Version:

Publisher's PDF, also known as Version of record

Document license:

Taverne

Please check the document version of this publication:

- A submitted manuscript is the version of the article upon submission and before peer-review. There can be important differences between the submitted version and the official published version of record.

People interested in the research are advised to contact the author for the final version of the publication, or visit the DOI to the publisher's website.

- The final author version and the galley proof are versions of the publication after peer review.

- The final published version features the final layout of the paper including the volume, issue and page numbers.

Link to publication

\footnotetext{
General rights rights.

- You may freely distribute the URL identifying the publication in the public portal. please follow below link for the End User Agreement:

www.umlib.nl/taverne-license

Take down policy

If you believe that this document breaches copyright please contact us at:

repository@maastrichtuniversity.nl

providing details and we will investigate your claim.
}

Copyright and moral rights for the publications made accessible in the public portal are retained by the authors and/or other copyright owners and it is a condition of accessing publications that users recognise and abide by the legal requirements associated with these

- Users may download and print one copy of any publication from the public portal for the purpose of private study or research.

- You may not further distribute the material or use it for any profit-making activity or commercial gain

If the publication is distributed under the terms of Article $25 \mathrm{fa}$ of the Dutch Copyright Act, indicated by the "Taverne" license above, 


\section{N. Vogels ${ }^{1}$ \\ G. Egger ${ }^{2}$ \\ G. Plasqui ${ }^{1}$}

K. R. Westerterp ${ }^{1}$

\section{Estimating Changes in Daily Physical Activity Levels over Time: Implication for Health Interventions from a Novel Approach}

\begin{abstract}
The aim of this study was to use a novel method to examine and compare physical activity levels in four different groups of men to investigate the impact of modernity on activity levels. Physical activity levels of four different groups of men were measured and compared, using a tri-axial accelerometer (Tracmor). The first group ( $\mathrm{HA}=$ historically active) were actors in a historical theme park who play the part of Australian settlers 150 years ago, the second were sedentary modern-day office workers (MS = modern sedentary), the third men who had successfully lost weight (SWL) in a modern men's weight loss program and the last, men who were unsuccessful (UWL) in the same program. Men who had successfully lost weight in a weight loss program were active at a level similar to that of men performing activity at a level carried out historically. Both of these groups were in turn signifi-
\end{abstract}

cantly more active than modern-day sedentary workers $(p<0.05)$ and men who had not been successful at losing weight $(p<0.01)$. A linear regression between weekly average activity levels and the degree of waist size loss showed a significant positive association $(r=0.52, p<0.01)$. The data suggest that a higher activity level facilitates the maintenance of long-term weight loss and this level is likely to approximate activity levels in the past. For the prevention and treatment of obesity an increase in physical activity is necessary, because (long-term) weight loss or weight maintenance is unlikely to occur when people are as sedentary as most people are today.

\section{Key words}

Physical activity $\cdot$ accelerometry $\cdot$ health intervention $\cdot$ weight loss

Fig. 1 is a graphical presentation of theoretical changes in energy expenditure in westernized countries over the last century. It could be assumed that there would have been noticeable increases in population physical activity levels during the depression and war years. Technological development and particularly the development of "time-saving" and "time-using" technologies [3] could have been expected to decrease activity levels from the mid 1950s on, and this would have been exacerbated by the advent of the Internet in the 1990s. However, while the pattern suggested in Fig. 1 is logically intuitive, there are no data to actually support this. (EE) [11] due to "time-saving" and "time-using" [3] technologies. one of the major pandemics of the 21st century [15]. It has a causal link with a range of different diseases [12], and is estimated to cost between $5-12 \%$ of the health budgets of many countries [4]. Obesity and overweight are caused by a chronic energy imbalance, which has been made more ubiquitous in modern times through "civilization" [2] or "modernity" [8]. Much of its recent aetiology is rooted in declining energy expenditure
Affiliation

${ }^{1}$ Department of Human Biology, Maastricht University, Maastricht, The Netherlands ${ }^{2}$ Department of Health Sciences, Deakin University, Melbourne, Australia

Correspondence

N. Vogels · Department of Human Biology, Maastricht University · PO BOX 616 - 6200 MD Maastricht . The Netherlands · Phone: + 31433882123 ·Fax: + 31433670976 ·E-mail: N.Vogels@HB.Unimaas.nl 


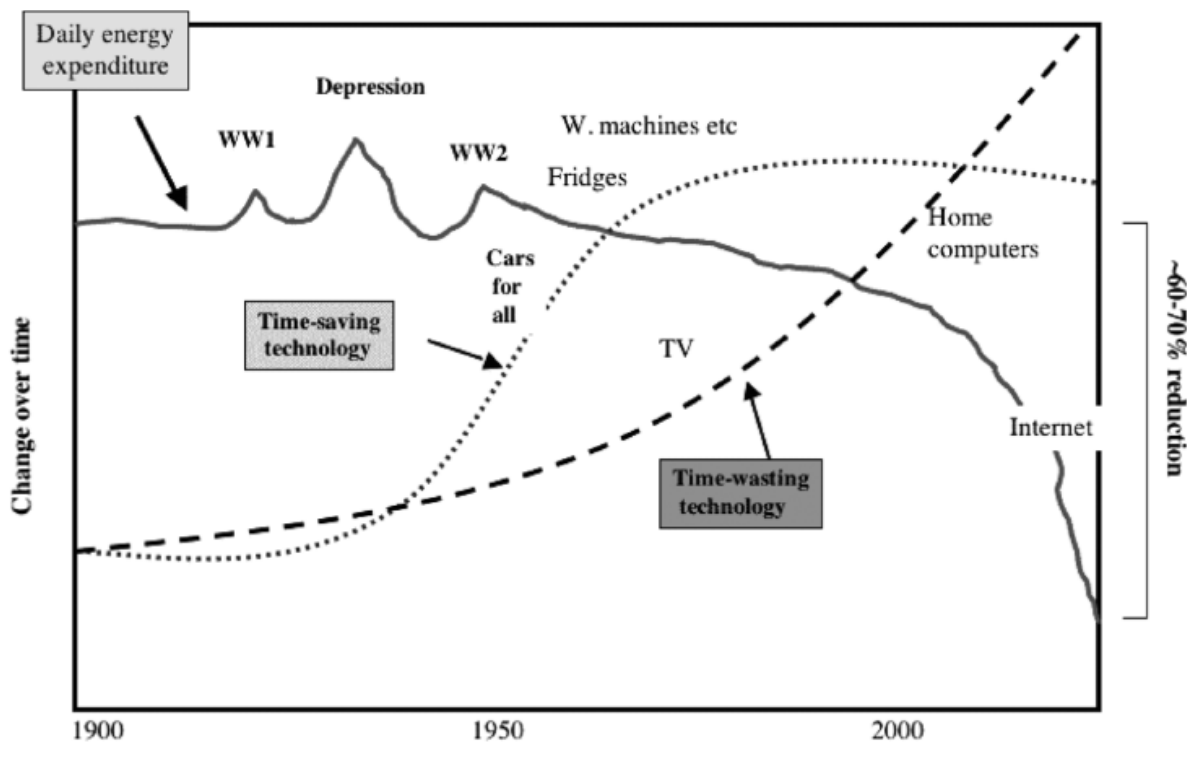

Fig. 1 Theoretical changes in population activity levels in industrialized countries over the 20th century.

Quantifying these secular changes in activity has been problematic, because of the difficulty of accurately measuring movement in free-living humans [13]. It is important to be able to do this in order to determine the extent of correction required for intervention guidelines aimed at improving health.

To our knowledge, only three reports have attempted to quantify differences in activity levels between ancient and modern cultures. Using comparisons of data between different cultures, Cordain [5] estimated a physical activity level (PAL), of up to 2.0 times basal metabolic rate (BMR) in traditional hunter-gatherers compared to 1.4 in modern sedentary individuals and $1.8-1.9$ in modern fitness enthusiasts and athletes. Calculations showed that this is equivalent to a difference in daily physical activity at the extremes, of walking $\sim 19 \mathrm{~km}$ per day. Hayes [7], examining activity levels in mammals, reached a similar conclusion. Suggestions were made that PAL levels in army recruits, Pima Indians, and Gambian farmers are near, or over 2.0, and in free-living mammals are up to 2.8, whereas those in US and European populations range from 1.2 (very sedentary) to 1.9 (young adults). James [9], on the basis of food disappearance data, estimated a change in energy expenditure of $\sim 800 \mathrm{kcal} /$ day in the last $20-$ 30 years. Based on the estimated energy expenditure of different activities for a 75-kg man [1], this would equate to a difference of walking $\sim 16 \mathrm{~km} / \mathrm{d}$.

To assess the validity of these estimates of PAL $[5,7,9]$, we used tri-axial accelerometers to measure physical activity levels in a small sample of Australian men encouraged to simulate the lifestyle of Australian settlers around 150 years ago. We compared this with a sample of modern sedentary workers. To assess the potential of intervening to reduce the impact of modernity on activity levels, we also tested another two groups of men. Men who had been successfully involved in a popular weight loss program, and men who had been unsuccessful.

\section{Methods}

\section{Subjects}

One group of men ( $\mathrm{HA}=$ historically active) were professional actors employed at an historical theme park ("Old Sydney Town") in Australia $(\mathrm{N}=7)$. To entertain the visitors of the park they played the roles of 19th century soldiers and peasants. Their daily activity level was high because they had to do everything for themselves, including chopping wood, finding and preparing food, and typical actions of soldiers and settlers of the day. For the purposes of this study, they were also asked to avoid the use of modern technology (cars, remote controls, TV computers etc) for the week of testing. To encourage compliance, up to 5 of the men lived in on-site facilities representative of circa 1850 for at least some portion of the week. A second group (MS = modern sedentary) were selected from typical modern sedentary occupations, including information technology, office work, and general medical practice $(\mathrm{N}=7)$. These men went about their normal business and were instructed not to do any extra activity. Two further groups were randomly selected from an established Australian men's weight loss program called "GutBusters" [6]. One group ( $\mathrm{SWL}=$ successful weight loss) had been successful in reducing waist size by at least $10 \%$ over a minimum of 12 months $(\mathrm{N}=13)$, largely through reducing fat intake (from around $35 \%$ of total energy intake to around 25\%) and increasing physical activity by walking. The second ( $\mathrm{UWL}=$ unsuccessful weight loss) had been unsuccessful, with a maximum waist size loss of $<5 \%$ $(\mathrm{N}=13)$.

\section{Measurements}

The Tracmor is a tri-axial accelerometer, which measures movement in three dimensions. The device weighs around $22 \mathrm{~g}$ and is worn on a belt around the waist. It has previously been validated against doubly labelled water [14]. The four groups of men used here aged 30-60, with a waist measurement no greater than $125 \mathrm{~cm}$, and with no overt illness, were asked to wear a Tracmor during waking hours over a period of one week. Recordings, in arbitrary activity units, were taken by downloading scores into a PC program customized for the device. 
The waist circumference was measured at the site of the smallest circumference between the rib cage and the ileac crest, with the subjects in standing position.

Body weight was measured on a digital balance (Seca, Hamburg, Germany; weighing accuracy of $0.1 \mathrm{~kg}$ ) with subjects in underwear, in a fasted state and after voiding their bladder.

\section{Statistical analysis}

Data are presented as mean \pm standard deviation (SD). Differences in mean activity levels between groups were pair-wise analysed by Independent-Samples $t$-Tests (SPSS 10.0 software). The Pearson correlation coefficient was calculated to determine the relationship between waist size loss and activity. Statistical significance for all analyses was set at $\mathrm{p}<0.05$.

\section{Results}

Characteristics of study participants are presented in Table $\mathbf{1}$ There was no significant difference in age, weight, and current waist size between the groups. Men who were successful at losing weight through the GutBuster program (SWL) were active at a level similar to that of men performing activity at a level carried out historically (HA). Both of these groups were in turn significantly more active than men who had not been successful at losing weight $(\mathrm{UWL})(\mathrm{p}<0.01)$ and the modern-day sedentary workers (MS) $(p<0.05)$ (Fig. 2). To investigate a possible relationship between weight loss and activity level a linear regression was executed between waist size loss and activity level of the SWL and UWL men (Fig. 3). There was a significant positive association between waist size loss and activity $(r=0.52$, $\mathrm{p}<0.01$ ).

\section{Discussion}

Our findings show a number of interesting points. In the first place, they support the obvious, but difficult to quantify conclusion that there have been significant decreases in human activity levels over time. Activity counts of the historically active (HA) group in this study averaged 1.6 times that of the modern sedentary workers (MS). If modern sedentary workers have an average PAL of 1.2, these findings would agree with suggestions of a PAL of 1.8-2.0 in fit individuals and hunter-gatherers [5]. This level corresponds with the activity levels of our historically active men (HA).

Calculations based upon estimations from Movahedi [10] and Ainsworth et al. [1] showed that the difference in activity level between the groups would imply a net difference equivalent to walking $\sim 8-16 \mathrm{~km}$ extra per day. At the upper level this figure would accord with that of Cordain et al. [5], Hayes [7] and James [9].

Recent recommendations suggest an added daily energy requirement of 30 minutes of accumulated mild-moderate intensity activity, for health benefits. However, for a 96-kg sedentary office worker, such as in this study, this would account for perhaps an extra $200 \mathrm{kcal} / \mathrm{d}$, which is $300-800 \mathrm{kcal}$ (or the equivalent of
Table 1 Characteristics of study participants (mean \pm standard deviation)

\begin{tabular}{|c|c|c|c|c|}
\hline & $H A^{1}$ & $M S^{2}$ & $S W L^{3}$ & $U W L^{4}$ \\
\hline Age (y) & $42 \pm 9$ & $44 \pm 11$ & $47 \pm 7$ & $49 \pm 6$ \\
\hline Weight (kg) & $88 \pm 6$ & $96 \pm 10$ & $89 \pm 8$ & $95 \pm 14$ \\
\hline $\begin{array}{l}\text { Starting waist size } \\
\text { (cm) }\end{array}$ & $N A^{5}$ & NA & $115 \pm 8$ & $108 \pm 8$ \\
\hline $\begin{array}{l}\text { Current waist size } \\
(\mathrm{cm})\end{array}$ & $95 \pm 8$ & $101 \pm 10$ & $97 \pm 8$ & $108 \pm 8$ \\
\hline $\begin{array}{l}\text { Total waist size loss } \\
\text { (\%) }\end{array}$ & NA & NA & $16 \pm 5$ & $0 \pm 3$ \\
\hline
\end{tabular}

${ }^{1}$ Historically active; ${ }^{2}$ Modern sedentary; ${ }^{3}$ Successful weight loss; ${ }^{4}$ Unsuccessful weight loss; ${ }^{5}$ Not applicable

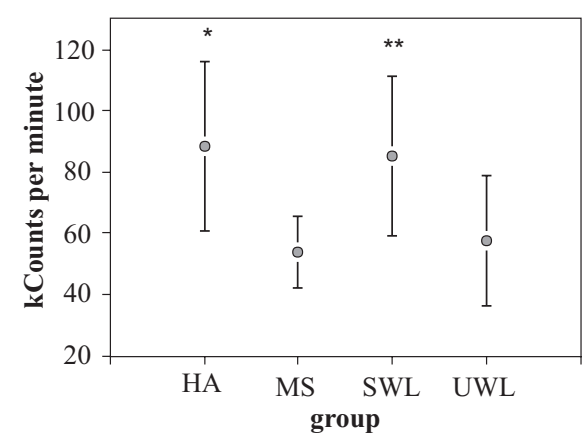

Fig. 2 Average weekly Tracmor output (kCounts per minute) and standard deviations for four groups of men: men performing activity at level carried out historically (HA); modern-day sedentary workers (MS); men who have successfully lost weight (SWL) and men who have not been successful at losing weight (UWL). Statistical significance was determined by Independent-Samples $t$-test between the groups HA and MS $\left({ }^{*} p<0.05\right)$, and the groups SWL and UWL $\left({ }^{* *} p<0.01\right)$.

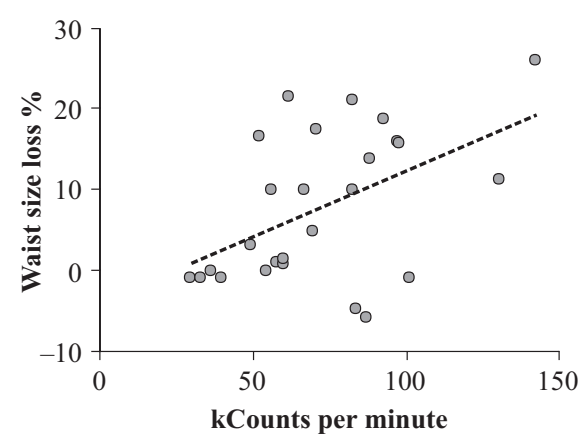

Fig. 3 Waist size loss (\%) of the men involved in the weight loss program as a function of physical activity level $(r=0.52, p<0.01)$.

walking 5-13 km) short of the $500-1000 \mathrm{kcal}$ difference estimated here. Of course weight maintenance can be achieved by reducing food intake and there are indications that this has happened over time, although with a discrepancy this great it is likely that energy imbalances would be easily created in some in- 
dividuals. It is therefore likely that current physical activity guidelines may not be enough to compensate for rapid changes in technology, at least in the absence of a significant decrease in energy intake (EI). Data from other studies also confirm this.

Activity levels of the successful weight loss group (SWL) were similar to those of the HA group, suggesting that increasing activity to levels more characteristic of previous time periods might have a positive effect on reducing body weight or remaining a healthy body weight. The change in diet (particularly reduced fat intake) could also help explain the loss in body weight in this group, but because dietary measures were not taken in this study this is difficult to determine. On the other hand, the unsuccessful weight loss group measured here (UWL) had an activity level over the week of testing more similar to that of the modern sedentary (MS) group. This would suggest that activity levels of modern sedentary workers are likely to be conducive to weight gain, particularly in the absence of a significant dietary change.

The ability of men in the SWL group to lose and maintain losses suggests that energy balance is possible in the modern environment without overly severe restriction. Successful men achieved a lower energy balance by increasing $\mathrm{EE}$ e.g. through walking, and decreasing energy intake, predominantly through reducing fat intake. Those who were unsuccessful have been typically found to be non-compliant with both EE and EI recommendations [6]. It seems that some conscious effort may need to be taken by many in modern environments to maintain a healthy body weight and that current physical activity guidelines, in the absence of significant EI reductions may not be enough.

The limitations of this type of study are obvious. However, the use of a simulated lifestyle to measure physical activity levels likely to be characteristic of human beings living in the past, may help add to the limited available information about changing activity levels over time. This, in turn, might help validate recommendations for physical activity in the present.

We conclude that declining levels of physical activity may be a key factor in the development of obesity in modern cultures. Despite the short period of measuring physical activity and the small sample size used in this study, our findings provide an indication of the importance of intervening to increase physical activity levels for weight maintenance with a "modern" lifestyle.

\section{Acknowledgements}

We would like to acknowledge Simone Drew from GutBusters for her assistance.

\section{References}

1 Ainsworth BE, Haskell WL, Whitt MC, Irwin ML, Swartz AM, Strath SJ, O'Brien WL, Bassett DR Jr, Schmitz KH, Emplaincourt PO, Jacobs DR Jr, Leon AS. Compendium of physical activities: an update of activity codes and MET intensities. Med Sci Sports Exerc 2000; 32: 498-504

2 Bjorntorp P, Rosmond R. Hypothalamic origin of the metabolic syndrome X. Ann N Y Acad Sci 1999; 892: $297-307$

${ }^{3}$ Bowden S, Offer A. Household appliances and the use of time: the United States and Britain since the 1920s. Economic History Review 1994; 47: 725 - 748

${ }^{4}$ Colditz G, Mariani A (eds). The Cost of Obesity and Sedentarism in the United States. Champaign: Human Kinetics, 2000

5 Cordain L, Gotshall RW, Eaton SB, Eaton SB 3rd. Physical activity, energy expenditure and fitness: an evolutionary perspective. Int J Sports Med 1998; 19: 328 - 335

${ }^{6}$ Egger G, Bolton A, O'Neill M, Freeman D. Effectiveness of an abdominal obesity reduction programme in men: the GutBuster "waist loss" programme. Int J Obes Relat Metab Disord 1996; 20: 227 - 231

7 Hayes M. Physical activity in mammals. Am J Clin Nutr 2002; 2: 369

${ }^{8}$ Hodge AM, Dowse GK, Koki G, Mavo B, Alpers MP, Zimmet PZ. Modernity and obesity in coastal and highland Papua New Guinea. Int J Obes Relat Metab Disord 1995; 19: 154-161

${ }^{9}$ James WP. A public health approach to the problem of obesity. Int J Obes Relat Metab Disord 1995; 19: 37-45

${ }^{10}$ Movahedi A. Simple formula for calculating basal energy expenditure. Nutr Res 1999; 19: 989-995

${ }_{11}$ Prentice A, Jebb S (eds). Physical Activity Level and Weight Control in Adults. Champaign: Human Kinetics, 2000

${ }^{12}$ Seidell JC (ed). The Burden of Obesity and its Sequelae. Philadelphia: Adis International, 1999

13 Tudor-Locke CE, Myers AM. Challenges and opportunities for measuring physical activity in sedentary adults. Sports Med 2001; 31: 91 100

${ }^{14}$ Westerterp KR. Pattern and intensity of physical activity. Nature 2001; 410: 539

${ }^{15}$ WHO. Obesity: preventing and managing the global epidemic. In: Report of a WHO Consultation. 2000; i - xii: 1-253 